\title{
Ensuring explosion safety of residential buildings
}

\author{
Vycheslav Gorev ${ }^{1, *}$ \\ ${ }^{1}$ Moscow State University of Civil Engineering, Yaroslavskoe shosse, 26, 129337, Moscow, Russia
}

\begin{abstract}
Explosions of air - and-gas mixtures in residential buildings incident dangerous and recently extended. Unlike the production explosive buildings residential buildings are not protected by express requirements. In this work the possibility of protection of these buildings by means of a depressurization through the coming-off apertures is analyzed. These apertures can be closed by windows or express light-weight constructions. In work it is shown that fastenings of these designs in an aperture considerably are reduced by effectiveness of opening of apertures as the incipient state of driving of protective designs does not open space for venting of gases. Explosion pressure at the same time grows as in closed volume and until opening can reach critical value and cause destruction of the protecting and load-bearing frames. By the time of opening of an aperture for venting of gases the Safety design already has sufficient speed, and discovery of the area in that case happens quickly and pressure increases slightly. The main pressure boost happens before destruction of fastening of mild designs and at their driving in an aperture when volume can be considered pressure-tight. Calculations show: that designs with the specific surface density $\rho_{\mathrm{p}} \geq 30 \mathrm{~kg} / \mathrm{m} 2$ and depth of seal of $\approx 0,2 \mathrm{~m}$ do not provide protection of residential buildings. The modern windows to double-glazed windows and their fastening are close to these conditions.
\end{abstract}

\section{Introduction}

Explosions of household gas in houses became the real national problem. Frequent reports from the place of events, messages about a death toll and the reasons of the incident force to be disturbed by the events and will mobilize to carrying out the analysis of the reasons and consequences of explosions of gas in premises.

The explosion dangers situation is formed as a result of the sequence of events: leak of combustible gas and its distribution in volume, ignition of explosive mix of gas with air, burning of explosive on gas mixture with simultaneous build-up of pressure indoors.

The modern civil engineering focused on electric furnaces and the centralized heat supply cardinally resolves explosion safety issues. However, in the majority of housing stock as multystoried and low, including a quotient, household gas is used.

\footnotetext{
*Corresponding author: kafedrapb@yandex.ru
} 
Cooking on fire, probably, forever will remain family and personal action. Therefore providing a explosion safety of residential buildings in connection with functioning of kitchen rooms needs to be considered and improved.

\section{Materials and methods}

Gas escape happens because of loss of leakproofness of system of supply of gas and failure of automatic equipment blocking supply of gas at leak and sudden extinction of combustion. The scale of losses strongly increases owing to the catastrophic collapses of heavy designs [1-4]. This collapse is often caused by destruction, loose couplings between overlapping and basic elements, or destruction, basic elements [5,6]. Consequences of explosion are defined by the following characteristics of designs and processes at explosion: the value and growth rate of pressure at explosion, a carrying capacity of the protecting designs and communications between these designs. The value of pressure of explosion is defined by properties of gas mixture, degree of gas contamination and process venting of the volume. Rate of increase of pressure is defined by the speed of explosive combustion. Many experimental works [7-11] and works in which this process numerically is modelled [12-16] are devoted to studying of this question. At explosion in closed volume terminal pressure of explosion is defined by a share of the burned-down substance.

$$
\frac{P_{(t)}-P_{0}}{P_{m}-P_{0}}=\frac{m_{(t)}}{m_{0}}
$$

Where $\mathrm{P}_{\mathrm{m}}$ - the maximal pressure of explosion of gas mixture. For estimates we will accept $\mathrm{P}_{\mathrm{m}}=800 \mathrm{kPa}, \mathrm{P}_{0}$ - initial pressure in volume of $\mathrm{P}_{0}=100 \mathrm{kPa}, \mathrm{m}_{0}$ - the mass of explosive mix at the complete gas contamination of volume, $\mathrm{m}_{(\mathrm{t})}$ - the mass of the burneddown mix by the moment of «t», $\mathrm{P}_{(\mathrm{t})}$ - pressure in volume by this moment of «t». If to accept that the allowed pressure $\Delta \mathrm{P}_{\mathrm{d}}$ - pressure up to which there are no destructions - is approximately, $7 \mathrm{kPa}$, then from (1) assessment turns out:

$$
\frac{\Delta P_{d}}{\Delta P_{m}}=\frac{m_{(t)}}{m_{0}}=10^{-2}
$$

This assessment shows that even at gas contamination 0.01 , that pressure of explosion already reaches admissible value. Estimated values of admissible pressure are defined by calculation on a carrying capacity for the first group of the limiting conditions $[17,18,6]$.

After derivation follows from expression (1):

$$
\frac{d \Delta P_{(t)}}{d t}=\Delta P_{m} \frac{4 \pi U_{g}^{3} \sigma^{2} t^{2}}{V_{0}}
$$

Expression (2) it is received in the assumption that the share of the burned-down substance is small, about $10^{-2}$, therefore density of original gas mixture is constant and equal to $\rho_{0}$, initial density. The center of inflaming has spherical shape, $\sigma$ - expansion ratio at combustion, that is the relation of density of original $\rho_{0}$ gas mixture to density of products of combustion. Follows from expression (2):

$$
\frac{\Delta P_{(t)}}{P_{0}}=\frac{4 \pi \gamma(\sigma-1) \sigma^{2}}{3 V_{0}} U_{g}{ }^{3} t^{3}=\gamma \frac{\sigma-1}{\sigma} \frac{V_{(t)}}{V_{0}}
$$


In expression (3) $\gamma=\frac{C_{p}}{C_{v}}$ in $\gamma=1.27$ products of combustion and at $\pi=\frac{P_{m}}{P_{0}}=8, \sigma=6.5$. From (3) it is visible that pressure on an incipient state of development of explosion grows in proportion to $\mathrm{U}_{\mathrm{g}}{ }^{3}, \mathrm{t}^{3}$, the value, $\gamma, \sigma$ and $\mathrm{V}_{0}$ known, and $\mathrm{V}_{(\mathrm{t})}-$ sphere volume from products of combustion.

Speed of explosive combustion of $U_{g}$ depends on many parameters. First of all from laminar flame propagation of gas mixture $\left(\mathrm{U}_{\mathrm{n}}\right)$. In the second turn it depends on turbulence level in an unburned gas before the combustion zone. Turbulence level generally from interaction of the stream of gases caused by expansion at combustion with barriers. At explosion at the petrochemical and chemical companies of a barrier play an important role in combustion acceleration. There they are in the free space and the stream flows round them. Another matter in kitchen rooms. Here barriers are located immediately at walls and the stream moves perpendicularly to walls where it stops and does not flow round a barrier completely. However, at a flame approaches to walls and barriers, its form deviates from spherical, the flame is deformed. The area of its surface at the same time increases, and it leads to increase in growth rate of pressure. As show results [19] it is increase slightly. Less than by 1.5 times. At weak turbulence in an unburned gas burning rate is defined by autoturbulization which in turn is defined by instability of a flame [19-22].

According to [21] burning rates under a condition $\frac{U_{n}}{U^{\prime}}>1$ and instability of a flame is defined by expression:

$$
\begin{gathered}
U_{g}=U_{n} \psi(\sigma) \ln \frac{U_{g} L_{m}}{a \sigma} \\
\psi(\sigma)=\frac{\sigma}{\sigma+1}\left(\sqrt{\sigma+1-\frac{1}{\sigma}}-1\right)=1.48, \sigma=6.5
\end{gathered}
$$

$\mathrm{L}_{\mathrm{m}}$ - the maximal mode at the front a flame, «a» - a thermal diffusivity.

At the emergency explosions especially on an incipient state of leak explosive mix is non-uniform, and burning rate at this moment depends from casual a leak condition. The instability and autoturbulization develop by the time of when number of Pecle $P e=\frac{U_{n} R}{a}>10^{5}[20]$. At combustion of air mixes, including natural gas the radius of the source reaches value of 4-5 meters that corresponds to the volume of $400 \mathrm{~m}^{3}$. Therefore, at combustion in the conditions of kitchen rooms autoturbulization until depressurization of volume will not occur. In [20] the maximum speed of combustion corresponding to the beginning of autoturbulization is estimated as

$$
\frac{U_{g}}{U_{n}}=3.1
$$

This assessment is an upper bound as in closed volume in kitchen rooms $\left(\mathrm{V}<400 \mathrm{~m}^{3}\right)$ autoturbulization does not occur.

In the offered work the possibility to lower explosive loadings to admissible value by means of a depressurization through the opening apertures is considered. These apertures have to be closed by mild designs which will be called further safety designs.

For effective implementation of the tasks Safety designs have to be quick-response and began to be opened with a pressure of opening which is less than the allowed pressure, and in the course of driving of Safety designs pressure in volume should not exceed allowed. 
Pressure of opening has to be as little as possible, but not less negative wind load capacity [23].

Expression (3) gives the chance to estimate time for achievement of pressure of opening $\Delta \mathrm{P}_{\mathrm{v}}$ and a first passage time of the allowed pressure for an explosion case in closed volume. Results of calculation are presented in table 1 on (3) time for achievement of pressure of opening of $\Delta \mathrm{P}_{\mathrm{v}}$ or the allowed $\Delta \mathrm{P}_{\mathrm{d}}$, for a case $\sigma=6.5, \mathrm{U}_{\mathrm{g}}=3.1 * 0.35=1.085 \mathrm{~m} / \mathrm{s}$ for various volumes of the room.

Table 1. Time for achievement of pressure of opening of $\Delta \mathrm{P}_{\mathrm{v}}$.

\begin{tabular}{|c|c|c|c|c|c|c|c|}
\hline $\begin{array}{c}\mathrm{V}, \mathrm{m}^{3} \\
\Delta P, \mathrm{kPa}\end{array}$ & 30 & 40 & 50 & 60 & 100 & 120 & 150 \\
\hline 2 & 0.0725 & 0.08 & 0086 & 0.091 & 0.108 & 0.115 & 0.124 \\
\hline 5 & 0.0984 & 0.109 & 0.117 & 0.123 & 0.147 & 0.156 & 0.167 \\
\hline 7 & 0.11 & 0.121 & 0.13 & 0.138 & 0.164 & 0.174 & 0.188 \\
\hline 10 & 0.124 & 0.137 & 0.147 & 0.156 & 0.185 & 0.197 & 0.21 \\
\hline 15 & 0.142 & 0.156 & 0.168 & 0.178 & 0.21 & 0.2255 & 0.243 \\
\hline
\end{tabular}

In table 1 time in seconds, achievements of pressure of explosion in the pressure-tight volume of $\mathrm{V} \mathrm{m}^{3}$ is given. The difference of values in lower line and in the line located above in the same column gives time necessary for a depressurization. It is necessary for efficient work of Safety designs that during this time pressure in volume did not increase from the opening pressure (the top line) up to the allowed pressure (the lower line). So, for example, for the volume of $50 \mathrm{~m}^{3}$ time difference between the third and first line $\Delta \mathrm{t}=0.13$ $0.086=0.044$ of sec. It means that the aperture has to be opened during this time and with a pressure opening of $\Delta \mathrm{P}_{\mathrm{v}}=2$ of $\mathrm{kPa}$, pressure in volume will not be exceeded by $7 \mathrm{kPa}$. Only quick-response designs which fasten loose couplings to a building framework can meet such strict conditions.

As Safety designs windows often are considered. Opening in window openings can happen in two ways:

1. Destruction of glasses with preservation of fastening of a window frame;

2. Having dug frames from an aperture with glazing preservation.

The destruction of glasses dependents on area, thickness and form of sheet of the glass. It is necessary to account for the number of sheet [23].

The modern windows with glass blocks have strong glazing and badly collapse that promotes increase in pressure of explosion above admissible.

In the presented work the option of driving of Safety designs is considered. In fig. 1 the general case of fastening of Safety designs in an external protection is presented. 


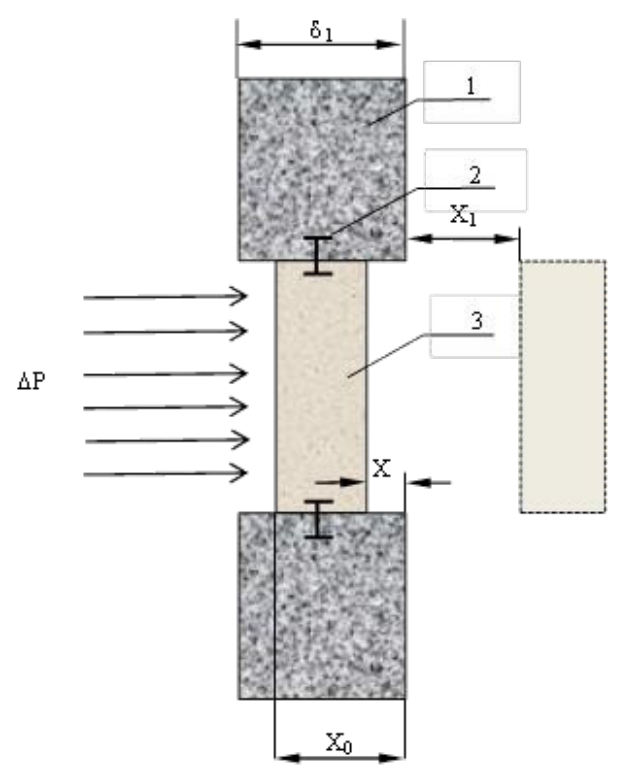

Fig. 1. 1 - a building wall, 2 - communication between a wall and the Safety designs (fastening knot), 3 - the Safety design, $4-\mathrm{X}_{0}-$ a path of the Safety designs prior to opening of an aperture.

The equation of motion of Safety designs on site $\mathrm{X}<\mathrm{X}_{0}$

$$
m \frac{d^{2} X}{d t^{2}}=a b P_{(t)}
$$

$\mathrm{m}$ - the mass of Safety designs, $\mathrm{a}^{*} \mathrm{~b}$ - the area of Safety designs, $\Delta \mathrm{P}_{(\mathrm{t})}-$ pressure operating on Safety designs from the moment of opening of $t_{v}$ until corresponding to $X=X_{0}$. Time is considered the moment of the beginning of opening of $t_{v}$ from the moment of initiation of explosion until destruction of fastenings of Safety designs, and began their movements.

The solution of the equation (6) on site $\mathrm{X} \leq \mathrm{X}_{0}$ is described by the equation:

$$
\bar{X}=\frac{B}{4}\left[\frac{(1+\theta)^{5}}{5}-\theta-\frac{1}{5}\right]
$$

$B=\frac{a b t_{v}{ }^{2} \Delta P_{v}}{m X_{0}} ; \Delta P_{v}-$ pressure operating on Safety designs, Pa; $t_{v}-$ time of opening, sec; $t_{v}=\frac{1}{U_{g}}\left[\frac{3 \Delta P_{v} V_{0}}{P_{0} 4 \pi \gamma(\sigma-1) \sigma^{2}}\right]^{1 / 3} ; \bar{X}=\frac{X}{X_{0}} ; \theta=\frac{t-t_{v}}{t_{v}}$.

After achievement the $\bar{X}=1$ space for the expiration of gases begins to open. Let's call this moment opening time $-\mathrm{t}_{0}$.

The first passage time of the moment of opening $\theta_{1}=\frac{t_{0}-t_{v}}{t_{v}}$ is defined from a condition:

$$
\frac{4}{B}=\left[\frac{\left(1+\theta_{1}\right)^{5}}{5}-\left(1+\theta_{1}\right)+\frac{4}{5}\right]
$$


Traveling speed of Safety designs at the time of opening $\bar{X}=1$ :

$$
\left.\frac{d \bar{X}}{d \theta}\right|_{\bar{X}=1}=\frac{B}{4}\left[\left(1+\theta_{1}\right)^{4}-1\right]
$$

After the beginning of opening of an aperture for the expiration of gases, an equation of motion will have an appearance:

$$
m \frac{d^{2} X_{1}}{d t^{2}}=a b \frac{\Delta P_{0 T}+\Delta P_{1}}{2}
$$

Where $\Delta \mathrm{P}_{0 \mathrm{~T}}$ - pressure in volume at the time of opening of an aperture. Starting conditions $X_{10}=0$ at $\mathrm{t}=0$. New timing and opening of an aperture, $\Delta \mathrm{P}_{1}-$ the maximal pressure in volume begins during driving of Safety designs after opening of an aperture, it should not be higher than admissible.

$\left.\frac{d X_{1}}{d t}\right|_{t=0}$ is defined from a condition (9). At the decision (10) was considered that there is a constant $\frac{\Delta P_{0 T}+\Delta P_{1}}{2}$ - an average arithmetic value that for mild Safety designs is acceptable.

The decision (10) in this case has an appearance:

$$
\begin{gathered}
X_{1}=\frac{a b}{m} \frac{\left(\Delta P_{0 T}+\Delta P_{1}\right)}{4} t^{2}+B_{1} t \\
B_{1}=\frac{B X_{0}}{4 t_{v}}\left[\left(1+\theta_{1}\right)^{4}-1\right] \text { or } \bar{B}_{1}=\frac{B}{4}\left[\left(1+\theta_{1}\right)^{4}-1\right]
\end{gathered}
$$

Value $\bar{B}_{1}$ is a dimensionless speed of Safety designs at the time of a departure from an aperture.

Time of opening of an aperture is defined from (8) for different «B». Value «B» changes over a wide range and defines time from the beginning of moving safety design before opening of on aperture. The it is less $\langle\mathrm{B}\rangle$, the more time moves the Safety design before opening of an aperture and therefore pressure in volume at the time of opening is higher.

So at:

$\mathrm{V}=100 \mathrm{~m}^{3}, \mathrm{~m} / \mathrm{ab}=10 \mathrm{~kg} / \mathrm{m}^{2}, \mathrm{X}_{0}=0.1 \mathrm{~m}, \mathrm{~B}=14.45$

$\mathrm{V}=30 \mathrm{~m}^{3}, \mathrm{~m} / \mathrm{ab}=30 \mathrm{~kg} / \mathrm{m}^{2}, \mathrm{X}_{0}=0.2 \mathrm{~m}, \mathrm{~B}=1.08$

The dependence of time on parameter $t_{0 T}=t_{v}\left(1+\theta_{1}\right)$ the relation $\frac{\Delta P_{0 T}}{\Delta P_{v}}=\left(1+\theta_{1}\right)^{3}$ and values on parameter $« \mathrm{~B} »$ is presented in table 2 .

Table 2. The dependence of time on parameter $t_{0 T}=t_{v}\left(1+\theta_{1}\right)$.

\begin{tabular}{|c|c|c|c|c|c|c|c|c|}
\hline $\mathrm{B}$ & 1.0 & 2.0 & 4.0 & 8.0 & 16.0 & 20.0 & 30.0 & 50 \\
\hline$t_{0} / t_{v}=\left(1+\theta_{1}\right)$ & 1.91 & 1.71 & 1.54 & 1.41 & 1.3 & 1.276 & 1.23 & 1.183 \\
\hline$\frac{\Delta P_{0 T}}{\Delta P_{v}}$ & 6.99 & 4.983 & 3.667 & 2.791 & 2.217 & 2.078 & 1.861 & 1.656 \\
\hline $\bar{B}$ & 3.091 & 3.755 & 4.654 & 5.86 & 7.566 & 8.255 & 9.666 & 11.982 \\
\hline
\end{tabular}


Further, accepting that $\Delta P_{0 T} \approx \Delta P_{1}$, that is fair for mild Safety designs, turns out:

$$
\begin{gathered}
\bar{X}_{1}=B \theta_{2}\left[\frac{\left(1+\theta_{1}\right)}{2} \theta_{2}+\left(1+\theta_{1}\right)^{4}-1\right] \\
\bar{X}_{1}=\frac{X_{1(t)}}{X_{0}} ; \theta_{2}=\frac{\Delta t_{2}}{\Delta t_{v}} .
\end{gathered}
$$

$\Delta t_{2}$-time of flight of Safety designs after opening of an aperture.

At opening an aperture from volume gases and pressure in volume begin to expire it will be described by expression [24]:

$$
\frac{d \pi}{d \theta_{2}}=3 \frac{\Delta P_{v}}{P_{0}}\left(1+\theta_{1}\right)^{2}\left(1+\frac{\theta_{2}}{1+\theta_{1}}\right)^{2}-\frac{\pi X_{1} t_{v}}{V_{0}} \frac{P_{0}^{1 / 2}}{\rho_{0}^{1 / 2}} 2^{1 / 2} \sqrt{\frac{\Delta P_{v}}{P_{0}}\left(1+\theta_{1}\right)^{3}+\pi}
$$

In this expression $\pi=\frac{\left(\Delta P_{(t)}-\Delta P_{0 T}\right)}{P_{0}}, \Delta \mathrm{t}_{\mathrm{v}}-$ time from the beginning of opening of an aperture after the Safety design moved to $\mathrm{X}_{0}$ distance, the value $\mathrm{X}_{1}$ undertakes from (12).

\section{Results}

From table 2 it is visible that opening pressure at the value "B" $\leq 8$ several times exceeds of beginning of the moving Safety design pressure, that is destruction of fastening of Safety designs.

It follows from the analysis of the equation (13) that after opening of apertures pressure of explosion increases slightly, and it is less, than pressure of opening of apertures $\left(P_{(t)}-P_{0 T}\right)<\Delta P_{o p}=\Delta P_{v}\left(1+\theta_{1}\right)^{3}$. Such situation, is a consequence of the fact that the Safety design speeds up $B_{1}=\frac{B X_{0}}{4 t_{v}}\left[\left(1+\theta^{\prime}\right)^{4}-1\right]$ by the time of opening of an aperture. The value of this speed reaches value about $20 \mathrm{~m} / \mathrm{sec}$. Such value of speed allows the Safety design to pass distance sufficient for a depressurization in time smaller, than opening time.

\section{Conclusion}

In work it is shown that fastening of the Safety designs intended for a depressurization in the depth of an aperture leads to the significant increase in pressure of explosion.

After destruction of the fastenings holding safety designs they move in an aperture, without opening space for the expiration of gases. At this time pressure in volume grows as in pressure-tight volume. In the majority of tests of Safety designs their fastening is carried out on a surface of the protecting designs. Such tests lead to mistakes in explosion pressure assessment several times. It results in excessively optimistic results.

Results of work allow to suggest to use as safety designs heat-insulating panels or sandwich - panels. Apertures can settle down between a ceiling and an upper of a window. Preference should be given to the apertures having as it is possible larger perimeter. Seal of the facilitated panels can be made on external side of the building. 


\section{References}

1. V. Marshall, Main dangers of chemical productions (World, Moscow, 1989)

2. U. Beyker, P. Cox, P. Uestrayn, D. Kulesh, R. Strehlow, Explosive phenomena: assessment and consequences, 2 tom (World, Moscow, 1988)

3. Accidents and disasters. Prevention and mitigation of consequences. Book 2 (DIA, Moscow, 1996)

4. L.P. Pilyugin, Designs of constructions of explosive productions (theoretical bases of projection) (Stroyizdat, Moscow, 1988)

5. L.P. Pilyugin, Prediction of consequences of internal emergency explosions (Pozhnauk, Moscow, 2010)

6. B.S. Rastorguyev, The manual for students of the higher educational institutions studying in "The production and civil engineering» the direction of training of certified specialists «Construction» (Moscow, 2007)

7. V.A. Gorev, V.N. Fedotov, Academy of Sciences of the USSR 6, 79-84 (1986)

8. P.S. Volpiani, T. Schmitt, O.Vermorel, P. Quillatre, D. Veynante, Combustion and Flame 186, 17-31 (2017) DOI: 10.1016/j.combustflame.2017.07.022

9. V.D. Sarli, A.D. Benedetto, Journal of Hazardous Materials 180(1-3), 71-78 (2010) https://doi.org/10.1016/j.jhazmat.2010.03.006

10. V.D. Sarli, A.D. Benedetto, G. Russo, S. Jarvis, E.J. Long, G.K. Hargrave, Flow Turbulence and Combustion 83(2), 227-250 (2010) DOI 10.1007/s10494-008-9198-3

11. O. Vermorel, P. Quillatre, T. Poinsot, Combustion and Flame 183, 207-223 (2017) ISSN 0010-2180, http://dx.doi.org/10.1016/j.combustflame.2017.05.014

12. A. Masri, S. Meares AlHarbi S. Ibrahim, Ind. Eng. Chem. Res. 51, 7690-7703 (2012)

13. T. Poinsot, Proceedings of the Combustion Institute 36(1), 1-28 (2017) https://doi.org/10.1016/j.proci.2016.05.007

14. P. Moin, S.V. Apte, AIAA Journal 44(4), 698-708 (2006) DOI: 10.2514/1.14606

15. S.B. Pope, New Journal of Physics 6(1) (2004) DOI: 10.1088/1367-2630/6/1/035

16. D. Bradley, How fast can we burn? In Twenty-Fourth Symp. (Intl) on Combustion (The Combustion Institute, 1992)

17. V.A. Gorev, A.I. Plotnikov, Stability at external emergency explosions. City structural complex and safety of life support of citizens (DIA, Moscow, 2005)

18. O.V. Luzhin, N.N. Popov, B.S. Rastorguyev, Dynamic calculation of constructions on express influences. Section 1. Calculation of designs of constructions on action of blast waves (Stroyizdat, Moscow, 1981)

19. N.A. Kakutkina, A.A. Kozzavin, V.V. Zamashchikov, A.A. Pleslov A.A., V.S. Babkin, Proceedings of the first international seminar. Moscow, 225-230 (1995)

20. D. Bradly, Proceedings of the second international seminar. Moscow, 51-59 (1998)

21. V.R. Kuznetsov, V.A. Sabelnikov, Turbulence and combustion (Publishing house Science, 1986)

22. V.A. Gorev, Fire and explosion safety 17(1), 12-16 (2008)

23. L.P. Pilyugin, Maintenance Explosion Proof buildings with relief designs (Association Fire safety and science, 2000)

24. V. Gorev, E. Salymova, Fire and Explosion Safety 26(5), 13-20 (2017) DOI: 10.18322/PVB.2017.26.05.13-20 